\title{
EXPERIÊNCIAS TEMPORAIS DA VITA ACTIVA E OS DESAFIOS DA TRANSMISSÃO INTERGERACIONAL
}

\author{
[VITA ACTIVA TEMPORAL EXPERIENCES \\ AND THE CHALLENGES OF INTERGENERATIONAL \\ TRANSMISSION]
}

José Sérgio Fonseca de Carvalho Professor Titular da Faculdade de Educação da Universidade de São Paulo

DOI: http://dx.doi.org/10.21680/1983-2109.2018v25n48ID14173

Natal, v. 25 , n. 48

Set.-Dez. 2018, p. 259-280

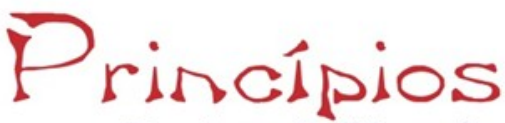

Revista de filosofia E-ISSN 1983-2109 
Resumo: Em seu prefácio à edição francesa de A Condição Humana, Paul Ricœur sugere a importância da temporalidade como categoria interpretativa das atividades humanas tal como Arendt as descreve. O presente artigo procura, a partir da exploração dessa chave interpretativa, vincular as experiências temporais da vita activa à responsabilidade política dos educadores em face dos recém-chegados e da durabilidade do mundo. Nele sugerimos que, para Arendt, seria precisamente na tensão e na complementariedade entre as dimensões temporais da experiência do animal laborans, do homo faber e do zoon politikon que se equilibraria a frágil possibilidade de que a política venha a se constituir como uma resposta digna à pluralidade como condição da vida comum e, assim, contrapor-se às tentações totalitárias.

Palavras-chave: Condição Humana; Ricœur; Temporalidade; Educação.

\begin{abstract}
In his foreword to the French edition of The Human Condition, Paul Ricœur suggests the importance of temporality as an interpretative category of Arendt's description of human activities. Departing from this interpretative key, the present article seeks to link the temporal experiences of Vita Activa to the political responsibility of educators towards the newcomers and the durability of the world. We suggest that it is precisely in the tension and complementarity estabilshed among the temporal dimensions of the animal laborans', the homo faber's and the zoon politikon's experiences that may flourish the fragile possibility of politics as a worthy response to plurality as a way of life in a common world..
\end{abstract}

Keywords: Human Condition; Ricœur; Temporality; Education. 
Em seu prefácio à edição francesa de $A$ condição humana, Paul Ricœur (1991a) sugere existir entre esta obra e As origens do totalitarismo um forte vínculo ou, para ser mais preciso, um laço de filiação (un lien de filiation). Em sua leitura, o primeiro grande livro de Arendt deixara em suspenso um problema essencial: sobre quais bases poderia o pensamento político se fiar para fazer face à hipótese totalitária da superfluidade do humano e às suas pretensões de um movimento incessante que transmuta o tudo é permitido em tudo é possível? Como pensar, pois, as condições de possibilidade de um mundo não-totalitário se a queda do regime nazista não eliminara definitivamente as tentações totalitárias? A condição humana seria, nesse sentido, a retomada, uma década depois, do desafio que ficara, então, pendente. Essa hipótese interpretativa inicial de Ricœur será por ele retomada com mais clareza e acuidade por ocasião da publicação, quatro anos mais tarde, de seu breve ensaio sobre o pensamento de Arendt intitulado "De la philosophie au politique", no qual afirma que, para a autora,

A possibilidade do mundo não totalitário deve ser procurada nos recursos de resistência e de renascimento contidos na condição humana. [...] A questão da filosofia, e mais precisamente da filosofia política, póseclosão totalitária se enuncia da seguinte forma: que barreiras e que recursos a condição humana, enquanto tal, pode opor à hipótese terrorista da plasticidade indefinida do homem-massa? (Ricœur, 1991b, p. 1)

Não é ocioso destacar que sua leitura vai de encontro às interpretações mais correntes entre os intelectuais franceses da época, que concebiam $A$ condição humana simplesmente como uma crítica, impregnada de nostalgia, à sociedade moderna ${ }^{1}$. Para Ricœur, ao contrário, $A$ condição humana não é um livro nostálgico, mas um exercício de pensamento que procura vislumbrar na durabi-

${ }^{1} \mathrm{O}$ próprio título da obra em sua edição francesa, La condition de l'homme moderne, contribui de forma significativa para esse viés interpretativo presente, por exemplo, nos comentários de Lebrun (1983) acerca do pensamento de Arendt. 
lidade do mundo e no legado político que herdamos do passado certos elementos capazes de apontar as condições de possibilidade para a existência de um mundo não totalitário no presente. Nele Arendt teria empreendido uma nova modalidade de antropologia filosófica, na qual a tarefa da filosofia não mais seria a de dissertar acerca de uma suposta natureza humana, mas a de ressaltar os traços mais duráveis da condição humana (Ricœur, 1991a) ${ }^{2}$. Traços que, em função de sua capacidade de permanência em meio às rápidas transformações sociais e econômicas que floresceram com a ascensão da era moderna, seriam apropriados para enfrentar pelo pensamento as hipóteses totalitárias da superfluidade do humano em um mundo despojado de estabilidade. A resistência às tentações do totalitarismo exigiria, pois, a transcendência temporal de um mundo comum cuja durabilidade pudesse abrigar a pluralidade como condição da ação; uma pluralidade, portanto, capaz de incorporar não só os agentes singulares do presente como aqueles que os antecederam e aqueles que os sucederão em um mundo comum.

Nesse sentido, Arendt teria tecido uma obra de resistência e de reconstrução, operando uma nova avaliação das atividades humanas que as considera não só em suas dimensões espaciais próprias, mas - sobretudo - em relação às diferentes experiências temporais que concorrem para que a vida do homo sapiens se erija como uma existência humana que se desenvolve em meio a um mundo durável. Um mundo que, para além de qualquer valor instrumental, tem a potencialidade de se erigir como um palco para a ação. É, pois, na tensão e na complementariedade entre as dimensões tem-

\footnotetext{
${ }^{2}$ Uma hipótese que encontra respaldo nas palavras finais do Prólogo de $A$ condição humana, no qual Arendt assevera: "Não discuto esse mundo moderno, que constitui o pano de fundo da redação deste livro. Limito-me, por um lado, a uma análise daquelas capacidades humanas gerais que provêm da condição humana e são permanentes, isto é, que não podem ser irremediavelmente perdidas enquanto não mudar a própria condição humana" (Arendt, 2011, p. 7; grifo nosso).
} 
porais da experiência do animal laborans, do homo faber e do zoon politikon que se equilibraria a frágil possibilidade de que a política venha a se constituir como uma resposta digna à pluralidade como condição da vida comum e, assim, contrapor-se às tentações totalitárias.

Ora, sejam quais forem as virtudes - ou os problemas - da leitura que Ricœur faz de $A$ condição humana, é inegável que, ao deslocar a centralidade das metáforas espaciais (domínio público, espaço privado, palco para a ação...) para privilegiar a análise da especificidade das experiências temporais de cada uma das atividades humanas fundamentais, o filósofo francês abre um campo interpretativo potencialmente fecundo e pouco explorado por aqueles que estudam o pensamento de Arendt. Não se trata de nele vislumbrar uma ontologia do tempo - diferentemente de Agostinho, ela jamais se pergunta "o que é o tempo?" - ou uma fenomenologia da consciência íntima da experiência temporal, como em alguma medida o faz o próprio Ricœur em Tempo e narrativa. $\mathrm{O}$ que sua obra nos oferece - e em especial toda a primeira parte de A condição humana - é uma análise elucidativa das dimensões temporais da existência humana tal como estas se manifestam no trabalho de seus corpos, na capacidade dos homens para edificar um mundo durável, na permanência dos princípios que inspiram suas ações e em sua capacidade de, por meio da política, romper com a reprodução do passado e iniciar algo novo, salvando o mundo da ruína inevitável que a passagem do tempo lhe infligiria. Não é, pois, para a consciência subjetiva de um tempo que passa e nos escapa que se voltam as reflexões de Arendt. Seu foco é, antes, a variedade de experiências existenciais de um ser temporal que, enquanto vivente, participa do ciclo sempiterno e, enquanto pessoa singular, constrói, habita e renova um mundo comum. Trata-se, assim, de pensar a experiência humana do viver-juntos-uns-aosoutros sob o horizonte do tempo.

É, pois, a partir dessa perspectiva interpretativa d'A condição humana que gostaria de tecer algumas reflexões que vinculam as 
diferentes experiências temporais da vita activa aos desafios da educação em um mundo que permanece, mais de setenta anos depois da derrocada do regime nazista, ameaçado pela tentação totalitária. A hipótese que guia este breve exercício de pensamento é a de que a essência da atividade educativa - o fato de que o mundo recebe o influxo contínuo de seres novos que nele devem ser iniciados - implica uma profunda responsabilidade política em relação à sua durabilidade. Trata-se de uma proposição que, à primeira vista, pode soar polêmica - eventualmente herética para alguns -, dada a convicção de Arendt acerca da necessária distinção entre a ação política e a atividade educativa ${ }^{3}$

Ocorre que essa cisão - decorrente da assimetria entre as responsabilidades daqueles que educam e dos que são educados e da rejeição a qualquer sorte de manipulação que vise substituir a ação política por um controle intergeracional - não esgota o problema das complexas relações entre política e educação no pensamento de Arendt. Seu equacionamento exige bem mais do que a mera evocação emblemática de uma ou duas passagens de seu texto sobre a crise da educação. A esse respeito vale lembrar que, já na abertura desse mesmo ensaio, Arendt nos alerta para o fato de que a crise da educação é um problema político de primeira grandeza, ressaltando, por exemplo, que o princípio da igualdade, firmemente ancorado no temperamento político norte-americano, impactou significativamente as relações educativas naquele país (Arendt, 1996). Como, pois, conciliar esse aparente paradoxo que caracterizaria a visão arendtiana das relações entre política e educação? Seria possível pensar a responsabilidade política da educação em face do mundo comum sem ceder à tentação da instrumentalização política da educação?

Creio que um primeiro passo no sentido da elucidação desse problema seria um esforço a fim de distinguir, em seu pensamento,

\footnotetext{
${ }^{3}$ Esse problema foi objeto de uma análise detida no artigo "Política e educação em Hannah Arendt: distinções, relações e tensões” (Carvalho, 2014).
} 
aquilo que diz respeito à natureza do processo de transmissão intergeracional de um legado de realizações materiais e simbólicas (as relações educativas) e o que diz respeito ao tipo de atitude que uma sociedade ou comunidade cultural cultiva em face dos recémchegados e do destino histórico de seu legado cultural (sua responsabilidade política no âmbito educacional).

Ora, as relações educativas dizem respeito a uma modalidade bastante específica de convívio: aquele que se desenvolve entre os que são mais velhos no mundo (e, por essa razão, assumem a responsabilidade coletiva por sua transmissão) e os que nele são os recém-chegados, cujos processos de progressiva familiarização, fruição e responsabilização pelo mundo são a razão de ser da educação. É precisamente em função dessa diferença em relação à responsabilidade que assumem pelo mundo - e em função da necessária proteção a esses recém-chegados - que as relações educativas são classificadas por Arendt como assimétricas e pré-políticas. Já a responsabilidade política pela educação diz respeito a um outro conjunto de problemas, ligado às decisões acerca das formas e conteúdos por meio dos quais uma comunidade cultural acolhe seus recém-chegados e a eles lega uma herança simbólica dotada de valor funcional, mas também de significado existencial e político. Nesse âmbito o que está em jogo não são as relações que se estabelecem entre gerações que convivem em um mundo comum, mas antes as escolhas que uma geração faz em relação aos modos pelos quais ela deverá iniciar aqueles que são novos no mundo - a geração de recém-chegados - em aspectos específicos de um legado simbólico ao qual ela atribui valor e significado.

Um claro exemplo desse tipo de responsabilidade política que se assume na educação dos mais novos são as opções curriculares que todas as sociedades dotadas de um sistema público de educação são levadas a fazer. Tais opções, para além de qualquer condicionante pragmático, sempre representam o esforço de uma geração para salvar da ruína do tempo certas formas específicas de saber (como as ciências ou a filosofia), certas linguagens (como a 
literatura ou o cinema) ou certas práticas que marcam uma sociedade (como princípios éticos ou políticos aos quais ela atribui louvor ou censura). As escolhas curriculares expressam, pois, a adoção de uma multiplicidade valores e pressupostos; alguns externos à escola (como demandas sociais, interesses econômicos, princípios políticos) e outros diretamente vinculados à cultura escolar (como tradições disciplinares, práticas pedagógicas etc.). Nesse sentido, é evidente que não há uma escolha curricular - seja em termos amplos, como no caso de uma política pública, seja em termos mais restritos, como na seleção de um livro didático ou de uma abordagem disciplinar - que não implique uma maior ou menor responsabilidade política em relação aos recém-chegados (Carvalho, 2017).

Tomemos, a título de exemplo dessa responsabilidade política, uma mudança recente e significativa nas diretrizes curriculares nacionais: a inclusão da história e da cultura afro-brasileira nos programas de ensino básico. ${ }^{4}$ Seja qual for a apreciação que se faça dessa iniciativa ou da forma pela qual tem sido operacionalizada, é inegável que se trata de uma ruptura com o legado eurocêntrico que dominava as orientações curriculares até então vigentes na escola brasileira. Como medida legal, ela é o resultado de uma luta política - travada no espaço público - cujos objetivos são o reconhecimento e a valorização, no currículo da escola básica, da história e das culturas dos povos africanos e afro-brasileiros. Nesse sentido, essa, como qualquer outra diretriz curricular, expressa uma responsabilidade política que toda e qualquer comunidade deve assumir em face de um mundo problemático ${ }^{5}$ e sempre rente à destruição. Representa ainda um certo olhar para o passado, condicionado pelos problemas e aspirações do presente e voltado para o futuro, na medida em que se dirige aos recém-chegados que

\footnotetext{
${ }^{4}$ Trata-se da Lei $n^{\circ} 10.639 / 2003$, posteriormente alterada pela Lei $n^{\circ} 11.645 /$ 2008.

${ }^{5}$ A expressão é do próprio Ricœur (1991b), referindo-se à ausência de referenciais seguros acerca do sentido, procedimentos e escolhas educacionais.
} 
nele sucederão aqueles que os educam. Trata-se, pois, de um vínculo com a dimensão temporal do mundo que se tece a partir de uma transmissão cultural.

A educação constitui, nesse sentido, uma forma de cuidado com o mundo. Ela expressa uma maneira pela qual os homens se esforçam por imprimir durabilidade às obras, linguagens, formas de compreensão, princípios políticos e acontecimentos memoráveis aos quais atribuem valor e significado. Ao tomar certos aspectos de uma forma de vida (bios) como objeto de uma transmissão educacional - seja informalmente, por meio da impregnação cultural ou de uma forma deliberada, como a escolarização - uma comunidade cultural, a educação atualiza seu compromisso tanto com o legado que recebeu do passado como com suas expectativas em relação ao futuro.

A educação é, pois, uma das mais importantes formas de zelar pela continuidade de um mundo. Uma continuidade que não se confunde com a manutenção do status quo (que o levaria à ruína), mas que se volta para criação das condições de possibilidade de um vínculo temporal entre o passado e o futuro, fazendo do mundo presente um palco relativamente estável e capaz de abrigar a ação política que o renova, imprimindo-lhe rumos inesperados. Como destaca Marc Le Ny (2013, p. 39):

[...] é precisamente porque os homens são capazes de agir que eles se expõem a uma trama temporal caótica; é precisamente porque o mundo é incessantemente transformado por acontecimentos repentinos, irreversíveis e imprevisíveis que sua durabilidade constitui uma tarefa política primordial.

A responsabilidade política da educação reside, pois, nesse duplo compromisso: por um lado, cabe-lhe zelar pela durabilidade do artifício humano; por outro, assumir a natalidade (como decorrência do fato de que novos seres humanos chegam constantemente ao mundo e nele são capazes de empreender algo novo e inesperado) como sua razão de ser. Ora, nem a durabilidade do mundo 
nem a natalidade podem ser compreendidos senão por referência às diferentes experiências temporais que estruturam a existência humana em suas diversas dimensões, que vão do pertencimento ao um ciclo vital recorrente à inserção em um mundo durável, mas permanentemente sujeito a rupturas decorrentes de capacidade humana de iniciar algo novo.

\section{As temporalidades da vita activa}

É significativo - sobretudo para a perspectiva adotada nestas reflexões - que Arendt termine o primeiro capítulo de $A$ condição humana com uma breve, mas profunda reflexão acerca do tempo e da mortalidade como elementos centrais da condição humana. E, embora ela o faça evocando a concepção grega sobre o lugar dos homens - os mortais - em um cosmos imortal, suas observações transcendem largamente uma informação histórica e apresentam, a despeito de sua especificidade concreta, uma experiência temporal com a qual tradição do pensamento ocidental irá tecer um longo, e muitas vezes conflituoso, diálogo:

Inserida em um cosmo onde tudo era imortal, a mortalidade tornou-se o emblema da existência humana. Os homens são "os mortais": as únicas coisas mortais que existem, porque, ao contrário dos animais, não existem apenas como membros de uma espécie cuja vida imortal é garantida pela procriação. A mortalidade dos homens reside no fato de que a vida individual, com uma história vital identificável desde o nascimento até a morte, advém da vida biológica. Essa vida individual difere de todas as outras coisas pelo curso retilíneo do seu movimento, que, por assim dizer, trespassa o movimento circular da vida biológica. É isto mortalidade: mover-se ao longo de uma linha reta em um universo em que tudo o que se move o faz em um sentido cíclico. (Arendt, 2011, p 24)

A mortalidade como condição humana deriva, pois, do fato de que, além de viventes inseridos na continuidade incessante do ciclo vital (zoé), os homens são também dotados de uma existência (biós) que transcorre em um mundo comum. Uma existência cujo caráter singular - expresso pela natalidade como surgimento de 
um novo alguém no mundo - rompe com a temporalidade circular do domínio da vida e cria uma modalidade de experiência temporal que lhe é específica: de caráter linear, marcada pela finitude e passível de ser narrada como uma história de vida (story) singular. Mas, porque se sabem dotados dessa trágica condição mortal, os homens aspiram à imortalidade, concebida como uma glória imorredoura, eventualmente atribuída às suas obras, mas, sobretudo, à grandeza de seus atos e palavras. Não se trata, contudo, da mesma sorte de imortalidade de que gozam os deuses; tampouco da eternidade do movimento cósmico em que se inserem.

A imortalidade humana - igualmente diferente da eternidade da alma almejada pelo pensamento cristão - é uma permanência terrena, de caráter mundano. Ela depende, em primeiro lugar, da capacidade humana de edificar um mundo que transcenda a vida individual de cada um que nele adentra pelo nascimento e que dele parte ao morrer; um mundo capaz de se transformar em um lar imortal para seres mortais. Mas esse lar imortal, além de conferir durabilidade às obras humanas, deve se constituir como o abrigo de uma memória pública capaz de perpetuar - pela lembrança reificada em narrativas, monumentos, obras - feitos e palavras que, por sua grandeza, transcendem a fugacidade das vidas individuais que os realizaram e as proferiram. Assim, a experiência temporal da imortalidade depende tanto da capacidade humana de agir como da existência de um mundo capaz de recordar feitos e palavras memoráveis; de cultivar a grandeza do passado como um legado que se faz presente. Ela depende, pois, da temporalidade histórica de homens que edificam um mundo e nele habitam e agem.

A busca pela imortalidade se vincula, assim, de forma direta à vita activa em todas as suas dimensões e a cada uma delas imprime uma experiência temporal específica. Na mais primária dessas dimensões - a vital - essa experiência é marcada pelo ritmo cíclico comum a qualquer organismo constantemente sujeito a necessidades que, uma vez satisfeitas, voltam a se manifestar (como o so- 
no, a fome etc.). A temporalidade da vida - assim como a da atividade do trabalho (labor) a ela vinculada - é, pois, despojada de rupturas e de acontecimentos, tomando a forma de um tempo vazio, caracterizado pela repetição de ciclos e ritmos biológicos aos quais os homens se encontram presos pela necessidade.

Tal como os frutos da vida, os produtos do trabalho, a despeito de sua tangibilidade, não possuem durabilidade. Seu destino é serem consumidos em prol do próprio ciclo vital que integram, sem deixar marcas de sua existência (como o pão que devoramos todas as manhãs e que se funde ao nosso organismo até se misturar ao ciclo vital que lhe deu origem). Assim, despojados de estabilidade própria, os frutos de trabalho aparecem e desaparecem no sempiterno e anônimo ciclo de produção e consumo que caracteriza a vida e o trabalho voltado para sua manutenção. É precisamente nessa característica temporal que eles diferem dos objetos de uso e ainda mais radicalmente dos objetos de arte - resultantes da atividade de fabricação (work).

Fica claro, pois, que embora Arendt recorra a justificativas relativas ao uso de cada um desses termos - labor e work - na maior parte das línguas europeias, o sentido de sua inusitada distinção reside fundamentalmente na experiência temporal vinculada a cada uma dessas atividades. Ora, se tanto a preparação do pão como a construção de uma casa são atividades humanas impregnadas de cultura, o que as distingue é o fato de que enquanto a primeira se destina ao consumo imediato, a segunda pode acompanhar a sucessão de várias gerações, servindo de abrigo estável ao longo do tempo, como o próprio mundo. Se o caráter cíclico da vida determina a recorrência sem fim da atividade do trabalho, a fabricação de objetos de uso é dotada de uma outra temporalidade, marcada pela linearidade que implica tanto um início como um fim (na dupla acepção de um término e de uma finalidade). Se a primeira se destina ao consumo imediato, a segunda tem a pretensão da durabilidade dos objetos de uso ou de fruição (como os objetos de arte). A durabilidade é, pois, a característica temporal 
da obra. Por essa razão, a obra, embora possa se desgastar, resiste a seu reiterado uso ao longo do tempo, enquanto o produto do trabalho visa seu consumo mais ou menos imediato.

Ora, é precisamente a durabilidade das obras humanas que permite a edificação de um mundo cuja existência temporal transcende à de seus edificadores. E, por essa razão, o mundo, concebido como o conjunto das produções humanas artificiais e duráveis, empresta estabilidade e objetividade à existência humana, inelutavelmente marcada pela efemeridade da vida e pela mutabilidade das condições políticas em que está sempre inserida. É, pois, o mundo que garante "a estabilidade e a solidez necessárias para abrigar a criatura mortal e instável que é o homem" (Arendt, 2011, p. 119); para que ele possa se desvelar em sua unicidade e empreender ações que o caracterizam como um ser capaz de iniciar algo novo. E, nesse sentido, a obra que edifica um mundo é a condição de possibilidade de uma existência humana. Isso porque é por seu intermédio que homens superam a condição estritamente biológica e cíclica da satisfação de suas as necessidades vitais para tecerem uma existência em meio às condições históricas e culturais sob as quais vieram a um mundo cujo significado não pode ser reduzido a uma mera instrumentalidade visando à perpetuação da vida:

O mundo de coisas feito pelo homem, o artifício humano construído pelo homo faber, torna-se um lar para os homens mortais, cuja estabilidade suportará e sobreviverá ao movimento de permanente mudança de suas vidas e ações, apenas na medida em que transcende a mera funcionalidade das coisas produzidas para o consumo e a mera utilidade dos objetos produzidos para o uso. (Arendt, 2011, p. 246)

Assim, mesmo que o homo faber - o fabricador de obras - se guie pela lógica utilitária dos meios e fins, o mundo que resulta de sua atividade a ultrapassa. Ele não se limita a um conjunto de objetos úteis; de meros instrumentos a sofisticar a produção da subsistência, como se houvesse entre vida e mundo uma relação de 
mera continuidade. $\mathrm{Na}$ qualidade de um legado simultaneamente material e simbólico, o mundo oferece uma nova dimensão - existencial e temporal - à condição humana e, por isso, implica uma ruptura. O mundo é, em si, um dos "milagres" que os homens, por serem eles próprios um initium, foram capazes a realizar. Edificar um mundo implica, pois, fabricar um ambiente artificial povoado de objetos de uso, mas também criar linguagens, instituições e objetos cujo significado simbólico ultrapassa largamente qualquer funcionalidade ou utilidade que possam ter em determinado contexto de uso ou consumo.

Os objetos de arte - que assim se caracterizam precisamente porque são retirados de seu uso cotidiano para serem apreciados e resguardados do desgaste que o tempo e o uso lhe infligiriam (como o manto Tupinambá exposto em um museu, ou um cachimbo que já não mais é um cachimbo...) - são o exemplo mais frisante desse esforço humano no sentido de imprimir uma durabilidade excepcional a algumas de suas criações a ponto de nelas materializar anelo humano pela imortalidade:

Dada sua excepcional permanência, as obras de arte são as mais intensamente mundanas de todas as coisas tangíveis; sua durabilidade permanece quase inalcançada pelo efeito corrosivo dos processos naturais, uma vez que não estão sujeitas ao uso por criaturas vivas, um uso que, na verdade, longe de realizar sua finalidade inerente - como a finalidade de uma cadeira é realizada quando alguém se senta nela -, só pode destruíla [...]. Em nenhuma outra parte, a mera durabilidade do mundo feito pelo homem aparece com tal pureza e claridade; em nenhuma outra parte, portanto, esse mundo-coisa se revela tão espetacularmente como a morada não mortal para seres mortais. É como se a estabilidade mundana se tornasse transparente na permanência da arte, de sorte que certo pressentimento de imortalidade - não a imortalidade da alma ou da vida, mas de algo imortal alcançado por mãos mortais - tornou-se tangivelmente presente para fulgurar e ser visto, soar e ser escutado, falar e ser lido. (Arendt, 2011, p. 209)

Em seu ensaio sobre a crise da cultura, Arendt (1996) destaca que o caráter cultural - ou artístico - de um objeto se vincula pre- 
cisamente à durabilidade de sua presença no mundo; à sua capacidade de desafiar a temporalidade da vida (que exige que as coisas pereçam em seu ciclo de consumo e regeneração) e contraporse à lógica instrumental (para a qual o valor do objeto reside em seu uso que, por sua vez, resulta em desgaste). Ora, obras de arte assim como outras modalidades de criações do espírito e das mãos humanas, como teorias científicas, obras filosóficas, instituições e práticas sociais - podem, também elas, resistir ao efeito corrosivo dos processos naturais a despeito de sua parca ou nula utilidade imediata para o processo vital. (É claro que sempre podemos atribuir um valor instrumental à leitura de Platão ou de um poema, mas não seria esse precisamente o sinal mais claro da destruição do mundo em favor da vida?) Sua permanência torna-se, assim, um elemento de vínculo temporal entre gerações que se sucedem em um mesmo mundo que "[t]ranscende a duração de nossa vida tanto no passado quanto no futuro, que preexistia à nossa chegada e sobre-viverá à nossa breve permanência nele" (Arendt, 2011, p. 68).

Ora, o caráter temporalmente transcendente do mundo implica a transmissão intergeracional de bens duráveis e úteis ; de técnicas e práticas sociais, mas também de empreendimentos intelectuais, crenças, princípios dotados de um significado existencial e político e não meramente de uma funcionalidade pragmática. E aqui reside um dos elementos centrais da responsabilidade política vinculada à educação. $\mathrm{O}$ acolhimento dos novos - os recém-chegados - em um mundo preexistente pressupõe sempre um duplo e paradoxal compromisso por parte do educador. Por um lado, é preciso zelar pela durabilidade desse mundo comum de heranças materiais e simbólicas no qual ele os acolhe e inicia. Por outro, cabe-lhe cuidar para que os que são novos no mundo possam vir a se inteirar dessa herança pública, apreciá-la, fruí-la e renová-la. É essa iniciação numa herança comum - de saberes, práticas, conhecimentos, costumes, princípios, enfim, de obras dotadas de durabilidade às quais uma comunidade cultural atribui grandeza, valor, mérito ou significado público - que constitui o objeto precípuo da atividade edu- 
cativa. Por isso, é só ao fazer dessa herança simbólica comum sua própria herança que cada novo alguém se constitui simultaneamente como um ser pertencente a um mundo comum e um sujeito que, ao nele se hospedar, é capaz de, a partir de seus atos e palavras, lhe imprimir uma nova configuração. Como bem resume Arendt (1996, p. 247):

A educação é o ponto em que decidimos se amamos o mundo o bastante para assumirmos a responsabilidade por ele e, com tal gesto, salvá-lo da ruína que seria inevitável não fossem a renovação e a vinda dos novos e dos jovens. A educação é também onde decidimos se amamos nossas crianças o bastante para não as expulsar de nosso mundo e abandoná-las a seus próprios recursos, e tampouco arrancar de suas mãos a oportunidade de empreender alguma coisa nova e imprevista para nós, preparando-as, em vez disso, com antecedência para a tarefa de renovar um mundo comum.

Note-se que tanto o amor ao mundo quanto o amor às crianças a que se refere Arendt não devem ser compreendidos como sentimentos pessoais ou íntimos. Eles são, antes, "uma espécie de disposição e de prazer em partilhar discursivamente os acontecimentos mundanos que, ao contrário da compreensão romântica do amor e do amor fraternal, não nos remete a nós mesmos, à nossa intimidade e nem nos amalgama coletivamente" (Aguiar, 2011, p. 138). Não se trata, pois, de uma afecção subjetiva, mas de um modo de se relacionar com esse espaço situado entre-os-homens, que é o mundo comum. Ambos são, portanto, formas complementares de realização da philia, uma espécie de amizade - ou de disposição para com o outro - concebida não como escolha íntima, mas como forma de partilha e pertencimento ao mundo, sempre mediada pela palavra, artifício propriamente humano que confere sentido aos objetos de uma cultura e às experiências que eles nos proporcionam:

Pois o mundo não é humano simplesmente por ter sido feito por seres humanos, e nem se torna humano porque a voz humana nele ressoa. Ele 
se humaniza apenas quando se tornou objeto de discurso. Por mais afetados que sejamos pelas coisas do mundo, por mais profundamente que elas possam nos instigar e estimular, elas só se tornam humanas para nós quando podemos discuti-las com nossos companheiros [...]. Humanizamos o que ocorre no mundo e em nós mesmos apenas ao falar, e no curso da fala aprendemos a ser humanos. (Arendt, 1997, p. 31)

Daí a importância, para a educação, de um compromisso tanto em relação ao cuidado para com as coisas do mundo - que nos chegam dos vastos domínios do passado -, quanto para com aqueles que nele aportam e formam uma nova geração de companheiros do mundo; tanto do amor mundi quanto da philia como princípios que presidem o intercâmbio entre as gerações responsável pela durabilidade do mundo. $\mathrm{O}$ amor ao mundo nos faculta fruir de uma herança de realizações sem a pretensão de possuí-la como um bem privado, enquanto a disposição amical nos possibilita compartilhar discursivamente os objetos materiais e simbólicos do mundo comum com os mais novos, sem a pretensão de formatar seus destinos futuros. Ao familiarizar os jovens com realizações simbólicas de um mundo comum, a formação escolar lhes confere a possibilidade de se libertarem das tiranias do presente e se inscreverem como uma nova geração, num fluxo temporal que comporta tanto continuidade quanto ruptura. E é exatamente em benefício daquilo que é novo e revolucionário em cada criança e em cada geração que a educação deve se comprometer com a durabilidade e a conservação do mundo, não preservando o status quo de uma ordem política e econômica, mas cuidando para que a ruína do tempo não se abata sobre os acontecimentos, os personagens, os saberes e as práticas que escolhemos imortalizar pelo seu ensino. É esse legado simbólico que nos chega do passado que permite, a um só tempo, que cada jovem se constitua como um ser singular na pluralidade do mundo e nele possa fazer eclodir algo de novo, de inesperado ou mesmo de revolucionário.

Assim, o sentido do ato educativo guarda, em si, a tensão entre duas temporalidades antagônicas e complementares: a do mundo 
público, que reclama a durabilidade, e a temporalidade inaugural da ação, que consiste em começar algo novo; a instaurar algo que, sem a intervenção da ação humana, não existiria. A temporalidade da ação é, pois, a do acontecimento que eclode rompendo com o processo de repetição ou recapitulação do passado, fazendo emergir o até então inusitado, o imprevisível. Ela instaura, na linearidade duradoura da temporalidade do mundo, a possibilidade do descontínuo.

Reconhecer a presença dessa tensão na atividade educativa não implica em concebê-la como sendo equiparável à ação. Na verdade, a educação ocupa um lugar ambíguo na vita activa. Não se trata da fabricação de pessoas ou cidadãos (por mais que essa seja a esperança de uma pletora de discursos pedagógicos) porque o objeto da educação não é uma matéria passível de receber uma forma final pré-concebida, como a madeira cujo processo controlado de fabricação dela faz uma cadeira ou uma mesa segundo um modelo pré-concebido. O objeto da educação, ao contrário, é sempre um sujeito; um alguém que não só é novo no mundo, mas que guarda em si a potencialidade de começar; que é, pois, em si mesmo um initium ${ }^{6}$. Mas esse novo alguém ainda não é plenamente um ser-do-mundo; ainda carece de uma familiarização com suas linguagens, princípios, práticas. É alguém que precisa ser iniciado na trama da temporalidade compartilhada de uma época e em seu modo de vida. E essa iniciação requer um tempo e um espaço de proteção, de livre desenvolvimento, em suma requer o que os gregos chamavam de skholé: um tempo e espaço liberado das necessidades da vida, mas também das responsabilidades do envolvimento na polis; no espaço público e comum no qual os homens agem.

\footnotetext{
6 "Por constituírem um initium, por serem recém-chegados e iniciadores em virtude do fato de terem nascido, os homens tomam iniciativas, são impelidos a agir. [Initium] ergo ut esset, creatus est homo, ante quem nullus fuit ("para que houvesse um início, o homem foi criado, sem que antes dele ninguém o fosse”), diz Agostinho em sua filosofia política." (Arendt, 2011, p. 219-220)
} 
A educação não é, pois, só um espaço intermediário. Ela é também um tempo intermediário. Um tempo que se desenrola entre o fato bruto da natalidade - ou seja, da constatação de que alguém novo veio ao mundo e nele aparece, com seu rosto singular como signo da unicidade de sua pessoa - e a atribuição a esse alguém de uma responsabilidade pessoal plena pelos seus atos e da responsabilidade política pelo curso do mundo. O processo educativo cessa, pois, com a assunção de que esse alguém que era novo no mundo já nele se inscreve integralmente e se encontra livre para agir. Porque ser livre e agir são uma única e mesma coisa e se manifestam em ato; nos feitos e palavras de um agente que se situa em um contexto mundano singular e em um tempo único e presente. O agente desvela quem ele é, portanto, no instante fugaz do ato, que sempre ocorre como interação e interlocução em uma teia de relações que se situa em um presente compartilhado.

A disposição para o agir exige, pois, uma abertura para o presente. Requer ainda a coragem necessária para deixar o espaço privado - com seu tempo familiar, conhecido e cotidiano - a fim de enfrentar o espaço público e a experiência temporal da ação, marcada pela imprevisibilidade e pela irreversibilidade. Uma experiência temporal cuja eclosão não resulta de uma causalidade radicada no passado e que tampouco pode ser justificada inteiramente por seus pretensos efeitos futuros, como se ela fosse apenas um meio para um fim que lhe é exterior. A ação, diferentemente da fabricação, encontra seu sentido no próprio ato presente, na medida em que este é capaz de afirmar - em atos e palavras que se manifestam na fugacidade do aqui e agora - os princípios em nome dos quais o agente atua. A luta pela igualdade, por exemplo, se trava por ações que a afirmem no presente e não por estratégias que a postergam para um futuro cuja realização poderia supostamente exigir a negação presente da igualdade ${ }^{7}$.

\footnotetext{
${ }^{7}$ Nisto reside o cerne da discordância de Arendt com a visão instrumental da política que concebe, por exemplo, a ditadura do proletariado como um meio para alcançar uma liberdade futura.
} 
O tempo da ação não é, pois, o da permanência e da durabilidade, como no caso da obra. Ele não deixa para a posteridade um objeto tangível, embora possa inspirar uma biografia enquanto narrativa da radical singularidade de um alguém inscrito em um mundo comum. Mas essa será sempre a biografia de um ser finito, ainda que em luta pela imortalidade. Uma imortalidade que talvez só lhe seja facultada na medida em que assuma a precariedade temporal de sua existência fugaz em um mundo durável. Mas não residiria precisamente nessa assunção a potencial grandeza de cada ser humano em sua luta legítima pela ambição da imortalidade de uma biografia singular que lhe foi conferida pelo simples dom da natalidade?

\section{Considerações finais}

A crise geral que acometeu o mundo moderno, alerta Arendt (1996), abrange vários aspectos da existência e da condição humana. No domínio das atividades educativas - e de sua responsabilidade política pela conservação e durabilidade do mundo - ela se manifesta como uma desorientação no que concerne à nossa relação com o passado e com sua transmissão às novas gerações, em grande medida como resultado do impacto, neste campo específico, da ruptura da tradição. Em seu ensaio sobre a crise da autoridade, Arendt ressalta um aspecto desse impacto cujos efeitos no problema que aqui examinamos não pode ser subestimado:

Com a perda da tradição perdemos o fio que nos guiou com segurança pelos vastos domínios do passado, mas esse fio foi também o grilhão que encadeou cada sucessiva geração a um aspecto predeterminado do passado. [...]. Mas não se pode negar que, sem uma ancoragem segura da tradição, $[. .$.$] toda a dimensão do passado fica exposta ao perigo. Esta-$ mos ameaçados pelo esquecimento e, um tal ouvido - além dos conteúdos que se poderiam perder - significaria que, humanamente falando, nós nos privaríamos de uma dimensão, a dimensão da profundidade na existência humana. Pois memória e profundidade são o mesmo, ou antes, a profundidade só pode ser alcançada pelo homem por meio da recordação. (Arendt, 1996, p. 94-95) 
Ora, se concebida como iniciação a um mundo comum - e não meramente como um investimento pessoal em capacidades e competências individuais - a formação educacional é inseparável da compreensão que um sujeito faz de sua inserção num fluxo temporal que se estende tanto em direção ao futuro quanto ao passado, ambos em diálogo com o presente. Negar aos recém-chegados o direito a se inteirar desse legado de experiências simbólicas que nos chega dos vastos domínios do passado equivale a abandoná-los a seus próprios recursos e condená-los à tirania das demandas de conformação à ordem do presente e aos reclamos do ciclo vital. Ao contrário, vislumbrá-la como uma oportunidade de diálogo com objetos da cultura - e com o contexto histórico em que eles se constituem como tais e são preservados para compor um legado simbólico potencialmente comum -, a formação escolar ganha um sentido que ultrapassa qualquer eventual finalidade pragmática que seus conteúdos possam conter. A essência do humanismo, nos recorda Arendt, é a cultura animi: o cultivo desinteressado do espírito e do gosto; da capacidade de fruir, apreciar e julgar as instituições e obras que integram nosso mundo comum. É, pois, no cultivo e na apreciação desse legado de experiências simbólicas que se materializa a responsabilidade política de uma educação identificada com a resistência à tentação totalitária em suas formas contemporâneas.

\section{Referências}

AGUIAR, O. A amizade como amor mundi em Hannah Arendt. O que nos faz pensar. Rio de Janeiro, v. 19, n. 28, dez. 2010, p. 131-144.

ARENDT, Hannah. Between the past and the future. New York: Penguin, 1996. 
ARENDT, Hannah. Homens em tempos sombrios. São Paulo: Companhia das Letras, 1997.

ARENDT, Hannah. A condição humana. Rio de Janeiro: Forense, 2011.

CARVALHO, José Sérgio Fonseca. Política e educação em Hannah Arendt: distinções, relações e tensões. Educ. Soc. Campinas, v. 35, n. 128, jul.-set. 2014, p. 629-996.

CARVALHO, José Sérgio Fonseca. Educação: uma herança sem testamento - Diálogos com o pensamento de Hannah Arendt. São Paulo: Perspectiva; FAPESP, 2017.

LE NY, Marc. Hannah Arendt: le temps politique des hommes. Paris: L'Harmattan, 2013.

LEBRUN, G. Passeios ao léu. São Paulo: Brasiliense, 1983.

RICOEUR, Paul. Préface à Condition de l'homme moderne. In: RICOEUR, Paul. Lectures 1: autour du politique. Paris: du Seuil, 1991a.

RICCEUR, Paul. De la philosophie au politique. In: RICCEUR, Paul. Lectures 1: autour du politique. Paris: du Seuil, 1991b.

Artigo recebido em 2/05/2018, aprovado em 16/05/2018 